\title{
Asimilación y rechazo de la filosofía francesa en Alemania. La recepción de Manfred Frank: romanticismo, hermenéutica y deconstrucción ${ }^{1}$
}

\author{
Assimilation and rejection of French philosophy \\ in Germany. The reception of Manfred Frank: \\ romanticism, hermeneutics, and deconstruction
}

Naím Garnica ${ }^{2}$

Universidad Nacional de Catamarca, Argentina

Recepción: 15 de octubre del 2017

Evaluación: 9 de abril del 2018

Aceptación: 24 de mayo del 2018

\footnotetext{
1 Artículo resultado del proyecto de investigación "La crítica estética: entre Teoría Crítica y postestructuralismo" (Secyt-UNCA, 2015-2017).

2 Licenciado en Filosofía, becario doctoral de CONICET, Docente en la Universidad Nacional de Catamarca, Facultad de Humanidades, Departamento de Filosofía; integrante del Consejo Nacional de Investigaciones Científicas y Técnicas y del Instituto de Investigación en Teorías del Arte y Estética.

Correo electrónico: naim_garnica@hotmail.com
}

Garnica, N. (2018). Asimilación y rechazo de la filosofía francesa en Alemania. La recepción de Manfred Frank: romanticismo, hermenéutica y deconstrucción. 


\section{Resumen}

El ensayo pretende reconstruir los debates filosóficos franco-alemanes de los años 80. La llegada del pensamiento francés de Derrida, Foucault, Lacan, etc., generó en la filosofía alemana la polaridad asimilación-rechazo. Sostenemos que dicha polaridad es producto del rechazo o integración de las propias tradiciones alemanas que los autores franceses poseen. En consecuencia, creemos que son claves las obras de Manfred Frank sobre el pensamiento francés para entender tanto el debate como sus derivaciones en las discusiones sobre modernidad-posmodernidad, sujeto-no-sujeto, deconstrucción-hermenéutica, racionalidad-irracionalidad.

Palabras clave: Subjetividad, Modernidad, Romanticismo, Individualidad, Post-estructuralismo.

\section{Abstract}

This essay tries to rebuild the French-German philosophical debates of the $80 \mathrm{~s}$. The arrival of the French thinking of Derrida, Foucault, Lacan, Althusser, among others, yielded the bipolarity assimilation-rejection in the German philosophy. We hold that such bipolarity is a product from the rejection or integration of the same German traditions that the French authors possess. In that way, the works of Manfred Frank about the French thinking are key to understand both the French-German debate and its derivations in the discussions about: modernity-postmodernity, Subject-No-subject, deconstruction-hermeneutics and rationality-irrationality. Such that, we first introduce, from the reconstructions of Allan Badiou and Gary Gutting, some characteristics from the French thinking that allow us to understand the assumptions Frank criticizes. Secondly, we point which are the critics that Frank did on the French thinking through the recovery of the Romantic Esthetics, in particular, of the concept of romantic individuality that could derive from the hermeneutics of Friedrich Schleiermacher. Finally, we propose to acknowledge two derivation that arose from the reception of the Post-structuralism of the works of Frank.

Keywords: Individuality, Structuralism, Philosophical Schools, Modernity, Romanticism. 


\section{Assimilation et rejet de la philosophie française en Allemagne. La réception de Manfred Frank: romantisme, herméneutique et déconstruction}

\section{Résumé}

L'essai tente de reconstruire les débats philosophiques franco-allemands des années 80. L'arrivée de la pensée française de Derrida, Foucault, Lacan, Althusser, entre autres, a généré la polarité assimilation-rejet au sein de la philosophie allemande. Nous soutenons que cette polarité est le résultat du rejet ou de l'intégration de leurs propres traditions allemandes, présentes chez les auteurs français. Dans ce sens, les œuvres de Manfred Frank à propos de la pensée française son clés dans la compréhension tantôt du débat franco-allemand comme de ses déclinaisons dans les discussions qui traitent: modernité-postmodernité, sujet-non-sujet, déconstruction-herméneutique, et rationalité-irrationalité. Avec ces objectifs, nous présentons tout d'abord, sur la base des reconstructions d'Alain Badiou et Gary Gutting, quelques caractéristiques de la pensée française qui nous permettent de comprendre les hypothèses critiquées par Frank. En deuxième lieu, nous précisons les critiques spécifiques que Franck fait à la pensée française à travers la récupération de l'esthétique romantique, et tout particulièrement du concept d'individualisme romantique qui pourrait se dériver de l'herméneutique de Friedrich Schleiermacher. Pour finir, nous proposons de reconnaître deux dérivations qui ont découlé de la façon dont le post-structuralisme des œuvres de Frank a été reçu.

Mots-clés : Individualité, Structuralisme, Écoles philosophiques, Modernité, Romantisme.

\section{Assimilação e rejeição da filosofia francesa na Alemanha. A recepção de Manfred Frank: romanticismo, hermenêutica e desconstrução}

\section{Resumo}

O ensaio pretende reconstruir os debates filosóficos franco-alemães dos anos 80. A chegada do pensamento francês de Derrida, Foucault, Lacan, Althusser, entre outros, gerou, na filosofia alemã, a polaridade assimilação-rejeição. Sustentamos que essa polaridade é produto da rejeição ou integração das 
próprias tradições alemãs que os autores franceses possuem. Nessa direção, as obras de Manfred Frank sobre o pensamento francês são chaves para entender tanto o debate franco-alemão como suas derivações nas discussões acerca da: modernidade-pós-modernidade, sujeito-não-sujeito, desconstruçãohermenêutica e racionalidade-irracionalidade. Para tais fins, primeiro apresentamos, a partir das reconstruções de Alain Badiou e Gary Gurring, algumas caraterísticas do pensamento francês que nos permitam entender os pressupostos que Frank crítica. Em segundo lugar, apontamos quais são as críticas que Frank realiza ao pensamento francês mediante a recuperação da estética romântica, em particular, do conceito de individualidade romântica que resulta da hermenêutica de Friedrich Schleiermacher. Por fim, propomos reconhecer duas derivações que resultaram da recepção do pós-estruturalismo das obras de Frank.

Palavras-chave: niilismo, eterno retorno, transvaloração, Nietzsche, ressentimento. 


\section{Introducción}

Los debates durante los años 80 en torno a la filosofía francesa de mayo del 68, a través de su recepción en la filosofía alemana, parecen articularse en función de la polaridad asimilación-rechazo. Mientras algunos como Habermas rechazaban de forma radical a los jóvenes filósofos franceses por considerarlos irracionalistas y conservadores, otros como Manfred Frank mostraban cierta ambivalencia en su recepción, en tanto consideraban algunos aspectos de la filosofía francesa que era vital incorporar ${ }^{3}$. Sin embargo, parece necesario reconstruir y caracterizar algunos elementos filosóficos previos a 1960, antes de abordar los debates y discusiones que la filosofía francesa despierta en las primeras recepciones en Alemania. En primer lugar, la intención es dar cuenta del estado de situación en el que la filosofía francesa llega a 1980. Algunos de los supuestos que la filosofía francesa contiene previo a 1960 serán claves para la recepción alemana, por lo cual se vuelve necesario señalarlos, al menos, de forma breve. Empleamos a tales efectos las reconstrucciones de la filosofía francesa de Gary Gutting y Alain Badiou para mostrar de qué modo la filosofía alemana es constitutiva de las consideraciones francesas.

En segundo lugar, pretendemos exponer que la filosofía alemana de la década del 80 se podría explicar bajo la fórmula expresada por Manfred Frank como "integración sin entusiasmo". Precisamente, nos concentramos en las consideraciones de Frank a los fines de entender las primeras recepciones de la filosofía francesa en Alemania. El contacto con la filosofía francesa de los 60 , no hace otra cosa que convertirse en un espejo para la filosofía alemana

\footnotetext{
3 Las relaciones intelectuales entre ambos países parecían mantener cierta fluidez si nos detenemos en los siglos XVIII y XIX, particularmente, en las opiniones alemanas sobre la literatura y la política francesa (Revolución e Ilustración). Pero dicha percepción parece modificarse a inicio del siglo XX. Ya en 1930, León Brunschvicg en el prólogo a Las tendencias actuales de la filosofía alemana de Georges Gurvitch, sostenía la necesidad de recuperar un diálogo perdido en las academias filosóficas por parte de estas corrientes de pensamiento. El pensador francés agradece el esfuerzo de Gurvitch de acercar al mundo intelectual francés lecciones sobre las discusiones y pensadores contemporáneos alemanes. Brunschvicg reconoce la necesidad de acercarse al nuevo panorama alemán, cuya emergencia será determinante en el siglo XX. También advierte que alemanes y franceses eran víctimas de sus respectivos pasados históricos, los cuales los sujetaban a sus propias necesidades de reelaborar la tradición. Al respecto Brunschvicg sostiene: "Como indicaba yo en una conferencia que recientemente tuve el alto honor de dar en la Universidad de Berlín, los alemanes y los franceses nos encontramos separados, no en modo alguno por nuestras preocupaciones actuales, sino por nuestro pasado o, más exactamente, por la manera de contarlo". (1939, p.8)
}

Garnica, N. (2018). Asimilación y rechazo de la filosofía francesa en Alemania.

La recepción de Manfred Frank: romanticismo, hermenéutica y deconstrucción.

Cuestiones de Filosofía, 4 (22), 37-67. 
donde el retorno de lo reprimido vuelve con fuerza ${ }^{4}$. Pese a ello, Frank ofrece algunos puntos de contacto entre su propuesta hermenéutica y el pensamiento francés a través del primer romanticismo alemán que parece necesario atender. En ese contexto, tratamos de evidenciar que la filosofía francesa no se convierte en un corpus difícil de absorber por su propia constitución, sino por lo impropio de lo propio que ella tiene para ofrecer en la Alemania de los años 80 . Finalmente, ofrecemos algunas de las derivaciones que se produjeron a partir del trabajo de Frank en relación a la filosofía francesa.

\section{La filosofía francesa antes de 1960. Dos lecturas.}

Algunos autores como Alain Badiou y Gary Gutting parecen coincidir en lo problemático que puede ser hablar de "filosofía francesa". Tal expresión, como lo marca Badiou, alude a lo siguiente: la falta de universalidad, la vocación euro-imperialista o el reniego de la etiqueta americana "french touch" o "French Theory" proveniente de los Cultural studies. Pese a la dificultad, podríamos distinguir como "filosofía francesa" el tipo de práctica filosófica particular elaborada en la segunda mitad del siglo XX. Como indica Badiou, "existen momentos de la filosofía, localizaciones particulares de la inventiva de la que ella es capaz y que poseen resonancia universal" (2013, p.10). Al igual que la filosofía griega y el idealismo alemán, la filosofía francesa marca una ruptura en la forma de creación, invención y práctica filosófica que la vuelve distintiva de otras variantes.

Sin embargo, Badiou cree en la necesidad de problematizar el supuesto conjunto de tradiciones de pensamiento que darían a la filosofía francesa su coherencia y validez. De los cuatro modos de indagar la "filosofía francesa", señalados por Badiou, -la cuestión del origen, las operaciones filosóficas inherentes a su identidad, la relación entre filosofía y literatura que le es constitutiva y, finalmente, una discusión permanente entre filosofía y psicoanálisis que la atraviesa- interesa desarrollar sólo las dos primeras formas. En este orden de ideas, la cuestión del origen y la de las operaciones filosóficas, nos permitirán caracterizar de qué manera el pensamiento francés, antes de 1960, se organizó con atención a la tradición alemana. Este último hecho es

\footnotetext{
4 Axel Honneth en una entrevista realizada por Simon Critchley $(2003$, p.247) no coincide con la hipótesis que aquí deslizamos. Honneth considera que la imagen del retorno de lo reprimido en la filosofía alemana puede tanto reducir las expresiones de otras corrientes como subestimar el papel de Heidegger en dicha filosofía.
} 
importante, pues explica parte del rechazo que recibe la filosofía francesa en el país germano durante su primera recepción.

La filosofía francesa, según Badiou, podría considerarse en sus inicios gracias a dos publicaciones que marcan el camino posterior. Por un lado, El pensamiento y lo moviente de Bergson y, por otro lado, Las etapas de la filosofía matemática, de 1912, del citado León Brunschvicg, las cuales, antes de la primera guerra, "le fijan al pensamiento orientaciones totalmente opuestas, al menos en apariencia" (Badiou, 2013, p. 12). Si esto se podría dividir diríamos que la primera opción plantea, a partir de la biología moderna, un pensamiento encargado de reflexionar en torno a la interioridad vital, donde ser y cambio se encuentran por medio de una identidad ontológica. Y, la segunda opción, mediante la matemática, sostiene una intuición conceptual que de algún modo explica la constitución de los simbolismos en la historia.

Para Badiou, esta última alternativa de filosofía "continuó durante todo el siglo con Lévi-Strauss, Althusser o Lacan, en un borde más "científico", con Derrida o Lyotard en otro más "artístico" (2013, p. 12). El resultado de estos caminos sería o bien la disyunción o bien la conjunción de una filosofía de la vida y una filosofía del concepto, dado que dicho enfrentamiento entre concepto y/o vida, nos remite, como indica Badiou, a una cuestión todavía más fundamental: la cuestión del sujeto. La vida como el concepto forman parte del sujeto, el cual se podría entender en este contexto como "un cuerpo vivo y un creador de conceptos" (Badiou, 2013, p. 13).

El trasfondo de los dos caminos abiertos por Bergson y Brunschvicg conduce a investigar sobre las condiciones del sujeto, esto es, su vida y pensamiento, la idea y el cuerpo, y otros binomios recurrentes en la filosofía francesa. Desde Sartre hasta llegar a Derrida, el sujeto es afirmado o negado en beneficio de la historia, de la estructura lingüística, de su reinvención, de su peligrosidad, o incluso, por su propia ausencia. Sin embargo, todavía aquí existe una necesidad de pensar en la herencia francesa, en aquella figura que le dio a la filosofía francesa la categoría filosófica del sujeto: Descartes. Por tanto, la herencia cartesiana de la cuestión del sujeto es una materia que la filosofía francesa durante el siglo XX se verá obligada a tratar: "el destino de la filosofía francesa, su división misma, es una división de la herencia cartesiana" (Badiou, 2013, p. 14).

El reconocimiento de Badiou de tal herencia pasará a un segundo plano si atendemos a la cuestión de las operaciones filosóficas. El pensador francés 
indica que el conjunto de la filosofía francesa, superando el legado cartesiano, consiste en una discusión sobre la herencia alemana. Este hecho lo pueden testimoniar las distintas producciones intelectuales de filósofos, artistas y poetas sobre el pensamiento alemán. Siguiendo a Vincet Descombes, podemos identificar pensadores franceses con su respectiva relación intelectual alemana. "La triple H" será una forma de organizar las respuestas buscadas por los filósofos franceses fuera de los márgenes del esquema propuesto por Descartes. En primer lugar, podemos destacar la influyente figura del filósofo de origen ruso Alexander Kojève, quien con sus lecciones sobre Hegel despertará en Francia un curioso interés por la consciencia y sus fracasos. Asimismo, dará cuenta de una reinterpretación sobre el concepto de autoconsciencia de la Fenomenología del espíritu. La lectura de Kojève(2008), pero también las de Jean Wahl y Jean Hyppolite sobre Hegel, indica que la consciencia jamás llega a una unidad absoluta ${ }^{5}$. La versión idealista del filósofo alemán señalaba cómo la consciencia se encontraba a sí misma luego de realizar el movimiento dialéctico.

A contrapelo de tal versión, los franceses suponen que la dialéctica en sí misma es pura negatividad, un movimiento que se desenvuelve, pero no para unirse en un momento superador. El movimiento dialéctico negativo constituye un desgarramiento del yo. Ese desplazamiento es, en cierta forma, un retiro desfigurador de la supuesta identidad que la consciencia adquiere al llegar hacia el final de su recorrido en la dialéctica. La razón de ese movimiento deformador radica en el modo en que la actividad dialéctica le es constitutiva una radical negatividad. Así, la dialéctica ostenta una fuerza que imposibilita la resolución de los estados anteriores en la unidad absoluta o espíritu. Aunque la interpretación de Kojève abrirá grandes posibilidades a una visión de Hegel en el contexto francés ${ }^{6}$, éste se convertirá en el blanco de ataque par excellence de las nuevas generaciones de filósofos, cuyos planteos -aunque

\footnotetext{
5 Por caso, Hyppolite considera que: "La conciencia de la vida, que se descubre que la vida, tal como se la presenta, no es auténtica vida sino sólo contingencia, se identifica aquí con la conciencia de la contradicción, es decir, con la conciencia del yo que está escindido internamente. Esta conciencia infeliz es la subjetividad, que aspira al reposo de la unidad; es la autoconciencia como conciencia de la vida y de lo que excede la vida. Pero sólo puede oscilar entre esos dos momentos". (1991, pp. 194-195).

6 Descombes señala: "En la versión que ofrece Kojève, el pensamiento hegeliano presenta algunos caracteres que podían seducir a un nietzscheano: tiene algo de aventurado y arriesgado, pone en peligro hasta la persona del pensador, su identidad, se sitúa más allá de la medida normalmente aceptada del bien y del mal". (1988, pp. 32-33).
} 
en muchos casos todavía respetuosos de la dialéctica- no concederán aspectos como la universalidad, la totalidad, la filosofía de la historia teleológica y la preeminencia de un sujeto dueño de sí en la historia?

En el caso de Husserl, se encuentra asociado en Francia con aquellos que han intentado pensar la fenomenología como Merleau-Ponty. Además de Husserl, ingresaban en su espectro de discusión Brentano, Kant y Spinoza, por lo que Husserl no era dominio exclusivo de quienes pretendían tomar a la fenomenología ${ }^{8}$ como una respuesta. Sartre y Derrida, por vías e intereses dispares, se encontrarán con Husserl. El camino seguido por la fenomenología de Husserl en Francia se extiende desde la complejidad del pensamiento de Merleau-Ponty hasta Derrida, pasando por Sartre, Marcel, Levinas, Wahl, hasta Ricoeur.

La fenomenología francesa introduce una variante existencial que ni la fenomenología ontológica, ni la trascendental podían ofrecer. Temas como el cuerpo, el Otro, la libertad, la interpretación, son indagados por medio de la fenomenología como metodología existencial. Waldenfels (1997) sostiene que la fenomenología existencial francesa podría entenderse también en relación a la hermenéutica del Dasein o, por lo menos, se asemeja bastante. Pese a ello, sostiene que dicho esquema podría ser reducido y limitado, si no atendemos a distintas tendencias que aparecieron ligadas a la fenomenología. Otro ejemplo, tal vez más emblemático de recepción alemana en el contexto francés antes de 1960 y posterior a esos años, es el de Martin Heidegger.

Gary Gutting en Pensando lo imposible no está tan seguro de afirmar una influencia determinante de Heidegger en el pensamiento francés. Si bien reconoce las declaraciones públicas de dos generaciones de filósofos como Sartre, Foucault y Derrida sobre la potencia del pensamiento heideggeriano en sus planteamientos, Gutting no cree que estos puedan decirse "discípulos".

\footnotetext{
7 Descombes sostiene que: "En 1968, todo lo moderno -es decir, siempre los mismos Marx, Freud, etc.,-- es hostil a Hegel, la diferencia entre las dos generaciones reside en esta inversión del signo bajo el que se establece la relación con Hegel: un signo menos reemplaza en todos lados al signo más" (1988, p. 33).

8 Waldenfels sostiene que "fueron ideas provenientes de Alemania las que causaron un verdadero cambio radical. En este proceso, Francia se benefició del éxodo de sabios del este de Europa, como Georges Gurvítch, Aron Gurwitsch, Alexandre Kojève, Alexandre Koyré, Eugéne Minkowski y Leo Schestow que, en su mayor parte a través de Alemania, habían encontrado el camino que los llevaría al vecino país occidental y que se encargaban de divulgar las nuevas ideas" (1997, p. 64).
}

Garnica, N. (2018). Asimilación y rechazo de la filosofía francesa en Alemania. La recepción de Manfred Frank: romanticismo, hermenéutica y deconstrucción. 
Indica que la lectura de Heidegger "fue incentivada no tanto por profesores como por figuras literarias que se sentían atraídas por Heidegger, fundamentalmente René Char y Maurice Blanchot" (2014, p. 104). Tal hecho evidenciaba que el pensador alemán era, necesariamente, una referencia para distintos filósofos franceses, pero no obligaba a estos a llevar a cabo un estudio disciplinado como alumnos.

La sugerencia de Gutting supone pensar que los franceses conocen parcelas de la obra de Heidegger, ya sea por la falta de traducciones o la mala circulación de sus textos. En cualquier caso, la influencia más notoria sobre los filósofos franceses puede ser la oscuridad de la escritura heideggeriana. Si Adorno, conjurando una crítica del lenguaje con la crítica de la ideología, le reclamaba ya a Heidegger el empleo de un "jerga" que terminaba exaltando una forma ideológica que ella misma pretende superar, algo similar les será reprochado a los filósofos franceses identificados con el post-estructuralismo. El problema radica en de qué modo esa "jerga" se ha vuelto ideología, esto es, "en la ontologización de condiciones históricas objetivas" (Raulet, 2006, p. 34). La insistencia de Heidegger en la dimensión ontológica olvida las condiciones sociales y comunicativas del lenguaje, además de volverlo oscuro y estetizante. Estos argumentos volverán a aparecer en las críticas de algunos pensadores alemanes a Derrida y los seguidores de la deconstrucción.

Gutting y Badiou sostienen que la incapacidad del siglo XIX en Francia "de producir filósofos franceses de categoría mundial” (2014, p. 129) obligó a prestar atención a "la triple H" (Hegel, Heidegger y Husserl) primero y a los maestros de la sospecha después. Los filósofos franceses de los años 60 comenzarán a tomar a Nietzsche, Marx y Freud a los fines de salir del esquema hegeliano, la hermenéutica y la fenomenología. Aunque la situación de las nuevas generaciones de filósofos franceses, posiblemente, tenga que ver con el tipo de sistema de enseñanza de la filosofía académica de esos años, como lo documenta Gutting.

Badiou afirma que la filosofía francesa encontró en Alemania "una nueva relación entre el concepto y la existencia; relación que adoptó variados nombres: deconstrucción, existencialismo, hermenéutica" (2013, p.15). La filosofía alemana proporcionaría los medios operacionales para llevar a cabo un desplazamiento, o invención, absolutamente nueva de la relación entre el concepto y la existencia. Este giro germánico tuvo efectos devastadores 
sobre la escritura y las tradiciones filosóficas francesas. Dicho giro terminó eclipsando a grandes figuras del pensamiento francés.

Si el momento que distinguimos como "filosofía francesa" encuentra sus condiciones de posibilidad más en nombres alemanes que franceses ¿dónde se ubica su estatuto propio? Si tenemos en cuenta la reconstrucción que acabamos de hacer ¿se enfrentan los filósofos alemanes de los años 80 a una recepción de la "filosofía francesa"? O ¿sólo son sometidos a escuchar sus propias tradiciones filosóficas de las cuales pretenden escapar por el peso del pasado? La recepción alemana de la filosofía francesa después de 1960 parece cargar con el prejuicio que los propios filósofos alemanes ya tenían sobre sus tradiciones. La sombra de Hegel y Heidegger, de Nietzsche, Marx y Freud vuelve a aparecer por medio de Derrida, Foucault, Lacan, Deleuze, entre otros. Lo propio de la filosofía alemana del siglo XIX y XX retorna en los planteamientos de la filosofía de Mayo del 68 y es rechazada como una forma impropia o poco original de hacer filosofía.

A nuestro juicio, es necesario hacer notar el papel jugado por Manfred Frank en la recepción alemana de estos franceses. El modo en que Frank presenta en sus lecciones al neoestructuralismo francés en Alemania será decisivo para varias generaciones de pensadores alemanes que tomarán a la filosofía francesa como un aire de cambio frente a las opciones de la Teoría Crítica y la Teoría de la Acción Comunicativa. Sin embargo, las caracterizaciones alemanas presentes en la filosofía francesa que acabamos de presentar en forma general, serán atendidas por Frank para ser sometidas a un duro juicio que deriva en un rechazo de estas tradiciones. A tales efectos, primero intentaremos dar cuenta de la recepción y cuestionamiento que Frank lleva a cabo en sus lecciones denominadas ¿Qué es el neoestructuralismo? Y, en segundo lugar, veremos la recuperación de la hermenéutica romántica como forma de oposición a la filosofía francesa de mayo del 68, haciendo foco sobre aspectos de la filosofía romántica, tales como la individualidad y la subjetividad.

\section{Manfred Frank: recepción, problematización y crítica de las fuentes neoestructuralistas.}

Entre 1983 y 1984, Manfred Frank publica las lecciones sobre filosofía francesa que fueron dictadas a inicios de los años 80 en Düsseldorf, Alemania, bajo el título Was ist Neostrukturalism? Esta obra constituye uno de los primeros intentos de la filosofía alemana contemporánea de acercarse al 
pensamiento francés producto de los años 60. A su vez, es una de las obras más reveladoras sobre la posición de Frank en torno a sus preocupaciones que aún hoy le acompañan, como asimismo, los supuestos desde los cuales las ha analizado. Por una parte, evidencia una lectura reconstructiva (hermenéutica constructiva) del neoestructuralismo, la cual se encuentra determinada por la hermenéutica de Schleiermacher. Por otra parte, reconsidera y cuestiona los conceptos de consciencia, autoconsciencia y sujeto del neoestructuralismo, a partir de los supuestos del neoidealista Dieter Henrich.

A su vez, puede advertirse en las lecciones de Frank que Sartre, la lectura de Peter Szondi sobre el romanticismo alemán y los propios románticos (Novalis, el joven Schelling y el joven Friedrich Schlegel) son un recurso de anticipación respecto de las "hipotéticas" novedades que el neoestructuralismo viene a develar. Lejos de considerarlo un pensamiento rupturista, Frank observa las distintas continuidades, analogías y paralelismos que los planteos de autores franceses tienen con tradiciones filosóficas anteriores, fundamentalmente, alemanas.

Las lecciones plantean un diálogo franco-alemán que en los años 80 se había desvanecido, más del lado alemán que del francés, en las dos corrientes predominantes de la filosofía alemana: la Teoría Crítica y la Hermenéutica. Su intención es recordarle a la filosofía europea "su compromiso a favor de lo universal" (Frank, 2011, p.11); una declaración desde la perspectiva hermenéutica que busca establecerse como norma. También, vincula planteos que a golpe de vista no son semejantes. Por caso, Frank sugiere que el concepto de historia como a priori histórico de Foucault "ya habría" estado planteado en Friedrich Schlegel y la lingüística alemana al preguntarse por el lenguaje como lo "históricamente trascendental".

Incluso, el concepto de "suplementariedad" de Derrida posee un antecedente en el reconocimiento de la crítica del arte romántica sobre la obra de arte como una carencia que debe ser complementada por la crítica. El recurso de asociar nombres y conceptos entre filósofos alemanes y franceses, por momentos reduccionista y, por otro, cercano a un nacionalismo filosófico en el disfraz de "ya lo había señalado...", aparece con frecuencia en el movimiento del diálogo. Su examen se concentra en la razón histórica de esta falta de intercambio filosófico entre Francia y Alemania. Dicho análisis muestra una búsqueda por reconstruir un interés teórico común entre Alemania y Francia al recuperar aquellos puntos de partida comunes e iniciar un diálogo con 
algunos de los más importantes teóricos deconstructivos franceses, aunque su lectura se presente de manera provocativa.

Frank nos conduce por un camino que él mismo considera poco seductor para el dogma de la filosofía post-estructuralista: sus fuentes. A su juicio, el pensamiento elaborado por los filósofos franceses se encuentra lejos de ser una ruptura definitiva con el estructuralismo clásico. Si en la versión norteamericana de la filosofía francesa se intentó señalar que la inauguración del post-estructuralismo venía a marcar el final del estructuralismo, Frank coloca el neo- para indicar que no hay tal distinción. Este autor bautiza a este movimiento con el prefijo neo- y no post- como habitualmente lo encontramos, dado que Frank entiende que, gracias a la tradición lingüística romántica alemana, existen más continuidades de las que podemos suponer entre Saussure y Derrida.

En ese contexto, deben distinguirse dos puntos esenciales en Saussure. El primero relacionado a que la lengua no es sustancia, sino forma, y el segundo que su concepto de estructura debe ser entendido bajo la clave de un juego diferencial de negaciones. Ambos puntos se encontrarán en las reflexiones de Derrida, pero modificados de un modo u otro. Con esto Frank no pretende diluir a Derrida en Saussure, antes bien, procura indicar las condiciones de posibilidad que el segundo permitió para la emergencia del neoestructuralismo. Aunque su coincidencia es fundamental, ya que ambos entienden la ausencia de límites en las oposiciones y diferencias en el lenguaje, la distancia entre ellos evidencia el tránsito hacia el neoestructuralismo.

En cuanto a Saussure, indica que el juego diferencial es producto de una consciencia colectiva. La unificación es entendida por los neoestructuralistas como una policía del lenguaje que controla y vigila la identidad de la estructura. Tal característica coincide con la metafísica y la negación del Otro. En esta línea teórica, Frank elabora una comparación similar entre la antropología de Levi-Strauss y el reparo casi bíblico de Schleiermacher acerca de que "ninguna forma de nueva invención es absolutamente nueva" (2011, p.70).

A partir de esas derivaciones, Frank intenta mostrar que las consecuencias del estructuralismo clásico y la antropología estructural preparan la escena neoestructuralista. De alguna manera, deja entrever la observación de que el neoestructuralismo es una variación rebelde de una misma secta. No obstante, con el correr de la exposición, esto se disipa al marcar las distancias con el estructuralismo. La bisagra entre estructuralismo y neoestructuralismo en 
la reconstrucción de Frank puede entenderse en virtud de que la estructura necesita ser pensada como descentralizada.

La inclusión de Derrida de una estructura sin centro se aleja de un significado trascendental a los fines de incluir a la significación en un juego infinito en su extensión. La privación de un centro no admite pensarlo como algo preexistente y necesario, como lo haría la metafísica, por el contrario, es una condición de la estructura en el juego de diferencias. El planteo de un juego diferencial en la estructura, como el de Derrida, intenta separarlo de la tradición filosófica que prioriza la negación como determinación (omnis determinatio est negatio). Un pensamiento de la diferencia debe poder pensar algo y, al mismo tiempo, su negación constitutiva, a los efectos de determinar su diferencia. Sin embargo, tal pensamiento no puede caer en el argumento de que tal determinación sea un principio extra-estructural y esencial de la estructura/texto. En consecuencia, una estructura descentralizada requiere de un complemento, de un elemento supletorio que pueda constituir esa carencia, a esto Derrida llama "suplementariedad".

$\mathrm{Al}$ respecto, Frank es cuidadoso. Indica que este concepto presenta dos particularidades. Por un lado, el suplemento es flotante y provisional, la interpretación añadida al texto "viene a ejercer una función vicaria (...) presenta de alguna manera una propuesta de cómo se podría sustituir el sentido central faltante del texto" (Frank, 2011, p.80). Y, por otro lado, esa añadidura frente a la falta no puede entenderse a modo de un encontrar. Si la interpretación añadida es un hallazgo, ello presupondría la presencia de un fundamento previo. Por el contrario, es un inventar, un agregado de la interpretación provisional y flotante. De allí que Frank lo acerque a la crítica de arte romántica en el que la poesía es un oscilar permanente que no puede definirse. Del mismo modo que la crítica romántica no puede definir un juicio determinante, optando por juzgar a la poesía poéticamente, la suplementariedad derridiana tampoco puede fijar un criterio desde el cual determinar la interpretación o el sentido.

También, la explicación crítica de las fuentes del neoestructuralismo conduce a Frank a cuestionar los conceptos de subjetividad y estructura. A lo largo de las lecciones, intenta impugnar el accord minimale entre estructuralismo y neoestructuralismo de que no existe un punto exacto desde el cual interpretar el mundo. Apropiándose de la prioridad otorgada por la hermenéutica al sujeto y de los planteos sobre la autoconsciencia de Henrich, Frank demuestra 
que el ataque de los teóricos franceses al sujeto autoconsciente prepara un enorme ejército en contra de un gran coro de hombres de paja9

Si como habíamos mencionado, antes de la década del 60 en la filosofía francesa la cuestión que se articulaba de fondo tenía que ver con el sujeto, en la recepción alemana de Frank no deja de ser distinto. Frank rechazará los argumentos del neoestructuralismo contra el sujeto, pero lo hará no sin antes rechazar a sus informantes alemanes: el antihumanismo de Heidegger, la crítica a la razón y la subjetividad de Nietzsche, como también la primacía del lenguaje en la elaboración psicoanalítica de Freud por medio de Lacan.

Según Frank, la categoría de "sujeto" que el neoestructuralismo pretende disolver no existe como tal. La reconstrucción del sujeto, a partir de la crisis de la metafísica y de la representación elaborada por Heidegger, Freud, Marx y Nietzsche, sumado a la filosofía del lenguaje de Wittgenstein, Searle y Austin, son para Frank un camino equivocado. Frank parece rechazar el sentido común de fines de los años 80 , y principios de la década del 90 , sobre el fin de todo lo que se conoce como moderno. La política de neologismos y prefijos que se colocan al lado de los conceptos elaborados en la modernidad parece remitir a un aparato explicativo de la llegada de un nuevo momento histórico o, al decir de Frank, "el sobrio huésped del posmodernismo" (2004, p. 11). Por tal motivo, Frank sostiene que se debería indagar los orígenes de la modernidad por fuera de la esquematización de la historia del ser de Heidegger y la crítica de la modernidad de Nietzsche.

Ante tales consecuencias, Frank exhibe la imposibilidad de abandonar cierta participación de la consciencia en la conformación de los significados históricos de las estructuras. El fracaso de la visión del sujeto del neoestructuralismo consiste en admitir fuerzas que el sujeto no domina, por ejemplo: la estructura, el campo, el discurso, la differánce o la episteme. La figura de un campo discursivo que habla por el sujeto tal vez abandone la autoreflexividad asignada al sujeto, pero ésta es transferida a la estructura o discurso. La crítica del sujeto histórico queda eclipsada, según Frank, porque vuelve a una vieja figura de la filosofía clásica del sujeto. Para Frank, "la subjetividad reprimida en la posición del individuo retorna como la subjetividad de la estructura que reflexiona y se transforma actuando: retorno de lo reprimido" (2011, p. 117).

\footnotetext{
9 Véase Robert Pippin (2005).
}

Garnica, N. (2018). Asimilación y rechazo de la filosofía francesa en Alemania. La recepción de Manfred Frank: romanticismo, hermenéutica y deconstrucción. 
A partir de estas consideraciones sobre la subjetividad, Frank se concentra en Derrida y su análisis de los textos de Husserl. Según el autor, tales textos pueden derivar una teoría de la consciencia y el sujeto. Pese a ello, su desarrollo previo se detiene en las dos fuentes que informan a los neoestructuralistas sobre el problema de la subjetividad: Nietzsche y Heidegger. El sujeto, a partir de estos dos autores, obtiene características determinadas: ficción, inconsciente, efecto, producto, etc., las cuales pretenden hacerlo desaparecer.

Frente a estos postulados, Frank sostiene que existió en la tradición filosófica una superación de estos planteos que pretenden criticar los neoestructuralistas, a saber, los primeros románticos alemanes. Estos autores "no piensan ya la autoconsciencia como una relación de reflexión (...) han descrito la autoconsciencia de manera uniforme como carente del Yo y como temporal" (2011, p.227). A juicio de Frank, en la filosofía contemporánea existe un consenso al cual él mismo se adheriría: el sujeto no es ya un candidato que podemos elegir para la explicación de las cosas. No es un punto de partida (Descartes) ni un puerto de llegada (Hegel).

Sin embargo, Frank no concuerda plenamente con este consenso, en la medida en que afirma identificar una equivocación en el análisis de la categoría de sujeto. Existen para este filósofo excepciones en la forma de apropiación del sujeto en la tradición filosófica, como el romanticismo alemán. Dicha corriente permitió pensar a la individualidad como forma de romper el dominio universalista y mecánico, de forma tal que el sujeto no se transforme en una reflexión cerrada en su propio autoconocimiento. A partir de la filosofía romántica, el pensador alemán trata de mostrar que subjetividad e individualidad no podrían ser equivalentes y que este equívoco de igualarlas radica en la aceptación del modelo de la filosofía de la reflexión que el neoestructuralismo asume para criticar la categoría de sujeto. A continuación, trataremos de evidenciar el camino que Frank sugiere mediante la filosofía romántica, tanto en sus lecciones sobre el neoestructuralismo como en otros textos de la década del 80 e inicios de los 90 .

\section{Romanticismo, hermenéutica y neoestructuralismo: individualidad y subjetividad.}

Si bien en sus lecciones Frank enfatiza de manera insistente que la evidencia póstuma de Saussure lo muestra cerca de las teorizaciones del lenguaje de Humboldt, Schleiermacher y el joven Schelling, debemos señalar que la 
filosofía romántica para este autor cumple un papel todavía más fundamental que simplemente anticipar al estructuralismo y neoestructuralismo. Respecto de ello, el pensador alemán parte de reconocer el error del neoestructuralismo al confiar la historia de la subjetividad a la opinión de Heidegger, quien la reduce a una voluntad de apoderarse del mundo y de sí mismo. El desconocimiento o falta de atención de Heidegger a la distinción romántica de una consciencia instauradora de una no instauradora, conduce al neoestructuralismo a confundir autoconocimiento (autoconsciencia) con auto-reflexión. El reverso de la auto-reflexión para los románticos no descansa en un fundamento claro y distinto, sino "en algo que en sí mismo no es reflexionado" (2011, p. 226). El neoestructuralismo desconoce la teoría pre-reflexiva "de manera que para él, el fenómeno de la subjetividad se reduce al totalmente distinto del autoconocimiento" (2011, p. 226).

Frank muestra hasta el final de sus lecciones de qué modo el objetivo del neoestructuralismo de quitarle la corona de rey de la filosofía al sujeto moderno no logra dar en el blanco. El enemigo creado por la filosofía francesa a partir de los maestros de la sospecha, particularmente Nietzsche, no es más que una ficción elaborada por ella misma. Derrida, Foucault y Deleuze no disponen de las armas necesarias para ese ataque, en gran medida por su desconocimiento de las teorías de la autoconsciencia romántica. Básicamente, contar la historia de la subjetividad como un desarrollo de interpretaciones sobre el Ser como presencia, hasta llegar al oscurecimiento u olvido del mismo en la autoconsciencia como presencia ante sí de la era moderna, constituye una falacia, además de ser "demasiado bella para ser verdad" (Frank, 2011, p.289).

Es inexacto que el romanticismo piense a la autoconsciencia como presencia ante sí. La teoría romántica, fundamentalmente, parte del escepticismo de una instancia segura para el Yo. Dicho fundamento no es inmediato ni tampoco presente, de modo tal que hace imposible un sistema del saber autoconsciente. Frank asevera que "les debemos la clara comprensión de la imposibilidad de pensar la familiaridad que la consciencia tiene consigo misma como una relación de reflexión [...] son de una calidad de la que no cae ni un reflejo sobre la obra de Derrida" (2011, p. 290). La filosofía romántica ha postulado que la consciencia no es productora de sí, expropiándole el derecho de autonomía y soberanía atribuida por el neoestructuralismo. A partir de esto, la consciencia se muestra lanzada y desnuda, sin tener el poder de determinarse a sí misma.

Garnica, N. (2018). Asimilación y rechazo de la filosofía francesa en Alemania. La recepción de Manfred Frank: romanticismo, hermenéutica y deconstrucción. 
Frank cree que Derrida se equivoca en relación con la subjetividad, en tanto la hace descansar en un modelo reflexivo de la consciencia. Una clara prueba aparece en Márgenes de la filosofía:

¿Qué es la consciencia? ¿Qué quiere decir consciencia? Lo más a menudo en la forma misma del querer decir no se ofrece al pensamiento bajo todas sus modificaciones más que como presencia para sí, percepción de sí misma de la presencia. Y lo que vale de la consciencia vale aquí de la existencia llamada subjetiva en general. De la misma manera que la categoría del sujeto no puede y no ha podido nunca pensarse sin la referencia a la presencia hypokeimenon o como ousia, etc., el sujeto como consciencia nunca ha podido anunciarse de otra manera que como presencia para sí mismo. (Derrida, 1995, p.51)

Lo que está afirmando es que el sujeto está inscrito y sujetado al lenguaje y sólo puede hablar en la medida en que se ajuste al lenguaje. Así, Derrida muestra la conformidad pasiva de un sujeto paralizado que deja la creación y la transgresión del significado al juego del significante. Tal concepción implica el abandono del sujeto a estructuras que lo exceden. Precisamente, Frank encuentra riesgosa esta concepción pues constituye un intento de explicar el sujeto a través de la lingüística y sus derivaciones. En su libro $L a$ piedra de toque de la individualidad, Frank advierte la peligrosa coincidencia entre las teorías post-estructuralistas del sujeto con aquellas críticas a la subjetividad de la Alemania de Weimar, como las de Klages, Spengler y Schmitt. La coincidencia entre ambas perspectivas reposa en la sustitución de una consciencia fundadora por una exaltación presubjetiva que se podría entender como inconsciente, différance, poder, entre otras, las cuales se ven motivadas por una fuerza dionisiaca inexplicable.

Por estas razones, Frank cree que el neoestructuralismo tiende a confundir los conceptos de Yo y sujeto con los de individuo y persona. Parte de esta confusión está inspirada en la reducción del sujeto a una explicación reflexiva mediante teorías egológicas de la autoconsciencia. Derrida repite, naturalmente por otras vías, el análisis de Hegel de la autoconsciencia como una forma de reflexión. En su propuesta de la différance, Derrida presenta una crítica irrevocable de la filosofía trascendental, la cual conduce a la no identidad, la no presencia, la ausencia de origen y la imposibilidad de exceder el mismo significado. Pese a ello, en su crítica aún participa, ex-negatio, un modelo de reflexión que percibe la autoconsciencia como una auto-presencia que puede ser deconstruida. Frank explica la crítica de la presencia de Derrida como una crítica absurda de la siguiente forma: 
La ventaja del modelo derridiano es que permite concebir la individualidad como una no identidad radical, aunque el pensador francés evita el término o lo equipara indiscriminadamente con el de subjetividad. En cambio, su modelo no posibilita concebir la individualidad como autoconsciente y, por lo tanto, referida a sí misma. Ello se debe a que la subjetividad -en absoluto de manera diferente a lo que ocurre con el reduccionismo analítico- se le plantea la alternativa o de ser coherente (semantizable), y depender así de la correspondiente articulación de los signos, o de desaparecer en el sinsentido (reductio ad absurdum). (...) es subjetividad, y eso quiere decir que es un epifenómeno de la articulación de los signos. (...) se impone discutir, (...), el que Derrida pueda mantener en el marco de su modelo el principio de que existe subjetividad. Primero, porque al igual que en el monismo neutral no se ve cómo la subjetividad pueda surgir del puro juego referencial, de no darse ya por supuesto como algo irreductible mismo (...) Segundo, porque su ataque a la idea de la autorreferencia presente es tan radical que ya no se explican unas condiciones mínimas del fenómeno de nuestra autofamiliaridad. Pero este ataque a la idea de presencia no sólo es radical sino, además, absurdo. Sin el retorno a un momento de relativa igualdad consigo mismo, en modo alguno podría comprobarse una diferenciación (...); carecería de criterios y no podría distinguirse del estado de inercia completa. (1995, p. 156)

A causa de esto, Frank señala que si Derrida ve la autoconsciencia como un intento de reflexión para obtener identidad y mantener su origen, esto es, el intento que se frustra continuamente porque en lugar de la presencia de sí lo único que hay es diferencia, entonces, hay una serie de problemas que se ponen de manifiesto.

Tales problemas son constitutivos al modelo de reflexión, incluso si, como en Derrida, el reflejo reflexivo se entiende como negativo. La crítica de Frank a Derrida, siguiendo al joven Schelling, intenta explicar que la autoconsciencia como resultado de la reflexión es falsa ${ }^{10}$. Según su perspectiva, no existe un criterio por el cual juzgar si los elementos cercanos son verdaderamente idénticos o no idénticos como en Derrida. Frank da cuenta de que la consciencia se fundó en aquello que Schelling denomina "Ser Inmemorial". Este concepto de Ser no implica una simple retirada a una ingenua y pre-semiótica autoconsciencia. En contraste, significa, como lo era también para Schleiermacher, que la autoconsciencia se determina como un signo de no presencia y diferencia, es decir, con algo que le es familiar, pero que al

${ }^{10}$ Véase Hauge (1990, pp. 597-601).

Garnica, N. (2018). Asimilación y rechazo de la filosofía francesa en Alemania. La recepción de Manfred Frank: romanticismo, hermenéutica y deconstrucción. 
mismo tiempo no puede reflejar ante sí. A su vez, siguiendo los pasos de Schleiermacher, Frank precisa que la autoconsciencia:

consiste en una determinación o precisión de la que ella misma no puede considerarse autora y que por lo mismo hay que calificarla de trascendente (...) al entenderse como lo que es, ya está marcada por la huella de un retraso respecto de aquello que la marca -su indisponible estar determinada-; es decir, se siente dependiente. Tan pronto como abre los ojos, ya está privada de su autopresencia y ya no cuenta como lugar de una verdad presente a sí misma suprahistóricamente, que contiene en sí todos los hechos del mundo histórico y los ofrece a pasos deductivos. (1995, p. 146)

Esta vuelta a la hermenéutica romántica de Schleiermacher, le permite a Frank advertir que la teoría de la consciencia ha fracasado en su intento de explicar los procesos de fundación del sujeto. Y, por tanto, la crítica a la teoría de la autoconsciencia también está fallida al aceptarla como la explicación de aquello que critican.

Frank destaca que la hermenéutica romántica, al igual que la deconstrucción derridiana, reconoce tanto la no identidad de los signos como los efectos que este hecho produce sobre el sujeto que se interpreta a sí mismo mediante tales signos. Sin embargo, a diferencia de la deconstrucción, la hermenéutica romántica, aunque mantenga una proyección de sentido abierta al futuro producto de la no identidad de los signos, puede registrar un punto indivisible que se puede designar con el nombre de individualidad. Tal individualidad explica la no identidad de los signos sin caer en la idea de una polisemia abierta al infinito. Antes bien, "la asignación individual de sentido a la síntesis de signos, que dispone el sustrato verbal y el sentido, supone siempre una sacudida y siempre desplaza las fronteras vigentes de la normalidad semántica" (Frank, 1995, p.155).

Frank intenta mostrar, a través de la idea de individualidad proveniente de la hermenéutica romántica, que la identidad semántica no desaparece "como podrían dar a entender las conclusiones precipitadas de la teoría derridiana sobre lenguaje y sujeto" (1995, p. 155). La individualidad, en el marco de la discusión semántica y de la subjetividad, se constituye en una opción para resistir "a la idealización rigorosa del sentido del signo" (1995, p. 160), pero también garantiza volver comprensibles las interpretaciones donde se halla sentido, en tanto no desecha la idea de la autoconsciencia. 
Entonces, no es casual que Frank, en el libro que estamos comentando, establezca como subtítulo Reflexiones sobre sujeto, persona e individuo con motivo de su certificado de defunción posmoderno. Dicho subtítulo testimonia la oposición a todos aquellos intentos por desvanecer la idea de individuo en beneficio del lenguaje, el habla poética, la estructura o el inconsciente. Así, Frank proyecta que "la cuestión de la identidad de la persona apunta over time - en la continuidad de su vida consciente- a una hermenéutica de su autocomprensión, cuyo perfiles sólo están sugeridos y cuya elaboración sigue siendo trabajo de futuros esfuerzos" (1995, p. 161).

A juicio de Frank, la insistencia de Derrida por mostrar los efectos diferenciales de la significación no sólo desplaza los conceptos tradicionales y fenomenológicos de la autopresencia, sino también ha conducido al abandono de la autoconsciencia y la subjetividad como orígenes del sentido. De acuerdo con la tradición subjetiva, la consciencia del yo lograría convertirse en un conocimiento objetivo para sí misma, por lo que el sujeto es un tipo de cosa única que podría fundamentarse en un acto de autopresentación. Tal concepción hacía que el sujeto se presentase a sí mismo como ningún otro objeto podría hacerlo. Pese a ello, la presencia de la presentación del yo nunca puede autogarantizarse como lo supone dicha tradición. Tal imposibilidad radica en que la reflexión y la representación introducen la diferencia. Derrida ha mostrado cómo una concepción de esta naturaleza sólo conduce a un retroceso infinito en la medida en que el sujeto debería reflexionarse a sí mismo, pero también a cada una de las instancias en las que se auto-objetiva ad infinitum.

En La diseminación, el pensador francés, refiriéndose a Mallarmé, advierte la existencia de operaciones en las que la existencia de una presencia voluntariamente realizada por un sujeto ya no podría tener lugar. Indica:

Cada vez que Mallarmé se sirve de la palabra «operación», no ocurre nada que pudiese ser sorprendido como acontecimiento presente, realidad, actividad, etc. El Mimo no hace nada, no hay acto (asesino o sexual), ni sujeto actuante ni, por lo tanto, paciente. Nada es. La palabra es no aparece en Mímica, sin embargo conjugada en el presente, en y sobre la «apariencia falsa de presente», salvo una vez, y bajo una forma que no es la del juicio de existencia y apenas la de la cópula predicativa ( $«$ iEs al poeta, suscitado por un desafío, a quien compete traducir!»). Y se ha observado la elipsis constante del verbo «ser» por parte de Mallarmé. Es complementaria de la frecuencia de la palabra «juego»; y la práctica del «juego» en la escritura mallarméana aparece en colusión con el apartamiento del «ser». El apartamiento del ser 
se define y se imprime literalmente en la diseminación, como diseminación. (Derrida 1997, p. 327)

En virtud de este tipo de concepciones, Frank intenta evidenciar de qué modo estructuralismo y post-estructuralismo "trascienden" el sujeto y sólo logran entenderlo como un simple efecto de la significación. Como ya indicamos anteriormente, Frank intenta dar cuenta de que el "neoestructuralismo" supone una continuidad del estructuralismo, pues, después de todo, ambos sostienen la desaparición del sujeto a partir de supuestos antisubjetivistas.

Ante estas posturas, Frank ofrece una salida a través de la hermenéutica como un contrapeso e, incluso, como complemento de las deficiencias que estructuralismo y neoestructuralismo ostentan. El camino que el pensador alemán postula es el de la hermenéutica de Friedrich Schleiemacher. Según su perspectiva, Schleiermacher fue el primero, desde la hermenéutica, en derivar de la orientación filosófica-lingüística el fracaso de la teoría de la consciencia. A partir de reconocer en la hermenéutica romántica la individualidad en términos interpretativos, la crisis de la autoconsciencia como principio y fundamento último de la certeza de su autoconocimiento y cómo la autoconsciencia no puede decirse autora de sí misma, Frank cree que esta hermenéutica es una opción que podría constituirse como una escapatoria frente a las alternativas del neoestructuralismo.

Schleiermacher suele considerarse el fundador de la tradición hermenéutica; sin embargo, en el marco de estas discusiones, no ha conseguido adeptos que profundizaran sobre sus aportes. Desafortunadamente, la recepción de Schleiermacher, como del romanticismo en general a través de las ciencias del espíritu, especialmente Dilthey, dificultó que la recepción de su obra hubiera sido más amplia, y los especialistas sólo se limitaron a reducirla a una hermenéutica "romántica" de la empatía. Entender la hermenéutica romántica de este modo condujo a calificarla como una hermenéutica ahistórica, psicologista e irracional. En consecuencia, Frank marca la necesidad de una revisión de las consideraciones de Schleiermacher, a los fines de redescubrir aquello que este filósofo y teólogo alemán designó como individualidad. Brevemente, reconstruiremos algunos de los aportes que Frank recupera de este pensador romántico para marcar la confrontación y el camino que este tipo de hermenéutica ofrecería frente a las explicaciones neoestructuralistas del sujeto y el lenguaje. 
En su interpretación de Schleiermacher, Frank sitúa como punto de partida el hecho de que la interpretación hermenéutica de la individualidad consigue evidenciar que la autoconsciencia es una determinación que se caracteriza por estar "marcada por la huella de un retraso respecto de aquello que la marca", como también está "privada de su autopresencia" (1995, pp. 145-6). Frente a los intentos del neoestructuralismo de situar el lenguaje como punto de partida de la crítica al concepto de subjetividad, la propuesta de la hermenéutica romántica es "poner en juego la interpretación individual del mundo de los interlocutores de la comunicación" (Frank, 1995, p. 147) ${ }^{11}$. De hecho, Schleiermacher indica cómo lo individual constituye aquello que no puede reducirse a una identidad entre la interpretación y lo que se interpreta, como tampoco es el eslabón final de una cadena de interpretaciones que derivan en una consciencia que determina el sentido de la interpretación. El pensador romántico se refiere a este proceso del siguiente modo:

Cada persona es una unidad completa de consciencia. En la medida en que la razón produce la cognición en una persona, es, como consciencia, producida solamente para esta persona. Lo que se produce con el carácter de esquematismo, sin embargo, se postula como válido para todos y, por lo tanto, estar en uno no corresponde a su carácter (Schleiermacher 1990, p. 64. Traducción nuestra).

El individuo se organiza a sí mismo al llevar a cabo actos de interpretación y, por lo tanto, se mantiene a sí mismo como una apertura que evidencia una falta de certeza de su propio conocimiento. En lugar de una mirada autorreflexiva, el sujeto es una falta o bien un 'hueco' en el ser. Así, el individuo en su trascendencia nunca puede ser capturado completamente en una representación, en tanto su irrepetibilidad como interpretación interpretativa lo impide.

A raíz de esta concepción, Frank enfatiza de qué modo el concepto de individualidad de Schleiermacher muestra la imposibilidad de una identidad y ordenamiento semántico del cual se podría derivar la idea de un sujeto auto-fundado. A contrapelo, lo individual da cuenta del impedimento de un "ordenamiento de lo universal", a modo de un cierre definitivo del concepto como en la dialéctica de Hegel. En todo caso, lo individual "sólo puede ser un elemento, cuya naturaleza es la de no dejar de ser elemento de ese orden (...) lo individual nunca puede obtenerse del concepto de universal, cual producto final de una cadena de derivaciones metodológicas" (Frank, 1995, p. 148).

\footnotetext{
11 Para ampliar las consideraciones sobre Schleiermacher ver Frank (1985).

Garnica, N. (2018). Asimilación y rechazo de la filosofía francesa en Alemania. La recepción de Manfred Frank: romanticismo, hermenéutica y deconstrucción. 
De este modo, los propósitos de Frank se hacen todavía más visibles. En primer lugar, está arremetiendo contra el concepto de lenguaje en el que "el lenguaje habla" al sujeto heideggeriano asumido por los neoestructuralistas. Tal radicalización de lo gramatical presenta el peligro de eliminar al sujeto hablante como productor de sentido. Sin embargo, Frank no asume que la idea del sujeto hablante deba entenderse como un sujeto autónomo y receptor de significado. Contra esta autonomía, sostiene que el significado sólo puede existir dentro de un sistema diferenciador de significantes y que el sujeto que habla siempre debe someterse al sistema existente.

En segundo lugar, Frank cree que si la individualidad no es subjetividad auto-reflexiva, entonces, esta última es siempre algo general que no puede oponerse a la sistematicidad. En contraste, la individualidad no puede pensarse como si fuera un elemento menor de una unidad superior, la individualidad nunca es un caso especial de una regla general. Ante los intentos neoestructuralistas - pero también de la filosofía analítica contemporánea- por señalar que la autoconsciencia deriva las manifestaciones lingüísticas de una regla general, el pensador alemán apela a la hermenéutica romántica para poner de relieve la falta de un criterio transindividual y metafísico para la identificación universal de las cosas particulares.

En consecuencia, la única posibilidad para pensar el funcionamiento del sentido del lenguaje radica en la interpretación individual, pues "tal interpretación interrumpe tanto la ensoñación hermenéutica del modelo de código estructuralista como el sueño analítico de una identidad semántica preestablecida de los términos, al emplear los cuales no nos limitamos a expresar nuestro mundo, sino que también lo esquematizamos activamente (y cada vez de forma diferente)" (Frank, 1995, p.147).

El individuo, como Frank lo entiende, está en gran medida en desacuerdo con la clásica perspectiva filosófica que lo ve como una unidad existente en sí mismo; por ejemplo, en la visión de Leibniz, donde lo individual y lo universal tienen, en principio, características idénticas. Precisamente, Frank, recuperando a Schleiermacher, supone que el individuo no puede ser entendido al modo de un núcleo de personalidad irrevocable. A su vez, tampoco existe un concepto de individuo al que se pueda llegar a través de un proceso de derivación de un ideal de razón. A juicio de Frank, las derivaciones filosóficas de esta concepción del individuo son la condición de posibilidad de cada enunciado. Así, la individualidad se sintetiza a partir de la estructura existente, 
pero, simultáneamente, sigue siendo inaprehensible. Por ello, Frank remarca que "los individuos no pueden deducirse de un concepto (...) por cuanto son ellos quienes, sobre todo con la interpretación, asignan su concepto al todo, descubriéndose como elementos del mismo. (...) el significado del todo no existe más que en la consciencia de los individuos (...)" (1995, p. 148).

Cabe señalar que bajo estos supuestos la individualidad es entendida como una expresión única que, creando un sentido, no puede deducirse de una estructura. No se puede aplicar ninguna regla para captar al individuo, pues el individuo sólo puede, como afirma Schleiermacher, ser adivinado. Pese a que este concepto resulta problemático, debido a la lectura irracionalista que se hace del mismo, la adivinación constituye antes que una empatía, un arte, pero un arte de la explicación (Kunst der Auslegung). La adivinación no posee un criterio superior que guía la verificación del sentido de forma correcta. Schleiermacher afirma que, producto de que no existe en todas las situaciones una regla conocida para dar sentido a una expresión, se exige una primera comprensión que necesita de adivinación. Este momento, esencialmente contingente e individual en la adquisición del lenguaje primario, no puede conducir a una forma definitiva de establecer una certeza intersubjetiva que aparezca en forma de "representaciones objetivas" 12 .

Finalmente, la vuelta de Frank a los aspectos de la tradición hermenéutica romántica antes señalados, sugiere que los primeros románticos podrían constituir un momento de la filosofía moderna que la crítica al sujeto moderno neoestructuralista no parece reconocer con demasiada profundidad. De hecho, Frank explica de qué forma la tradición que abarca desde los primeros románticos hasta, probablemente, Sartre ha marcado la autoconsciencia como "prerreflexiva". Tal consideración sobre la autoconsciencia implica que el conocimiento involucrado en la autoconsciencia no es mediado a través de algún conocimiento reflexivo sobre sí mismo. En todo caso:

tengo consciencia de sí no sólo cuando estoy con conocimiento atento a mi consciencia de una manera explícita. (...) "Pre-reflexiva" significa, además, que en el origen ninguna autoconsciencia, como una distinción sujeto-objeto, se encuentra; para el fin de tener conocimiento de sí mismo, la consciencia no tiene por qué convertirse en objeto de una segunda consciencia propia (para un sujeto-consciencia) (Frank, 1997, pp. 6-7. Traducción nuestra).

\footnotetext{
${ }^{12}$ Seguimos aquí las reflexiones de Bowie (1996).
}

Garnica, N. (2018). Asimilación y rechazo de la filosofía francesa en Alemania. La recepción de Manfred Frank: romanticismo, hermenéutica y deconstrucción. 
Las preguntas sobre el fundamento del significado y la verdad son más productivas cuando observamos cómo los románticos advertían la precedencia de la revelación del mundo antes que de la semántica formal. Tal hecho está relacionado con que la revelación sólo es posible a través de sujetos autoconscientes que son capaces de interpretar y establecer significados, en lugar de comportarse en conformidad con las estructuras del lenguaje. Esto conduce a la necesidad de una revisión de la filosofía romántica ${ }^{13}$, en particular, de las observaciones metafísicas sobre la subjetividad. Pero tal exigencia no parece apropiada de profundizar aquí. Sin embargo, la sugerencia de Frank en su polémica contra el neoestructuralismo está franqueada por dicha preocupación.

\section{A modo de cierre: dos derivaciones del neoestructuralismo en la filosofía alemana.}

Pese a lo antes indicado, Frank (1988, $1998^{14}$ y 2004a) irá menguando su ataque a la filosofía francesa mediante una lectura de sus propias lecciones. Reconocerá que las lecciones estaban dispuestas para establecer un diálogo con la nueva filosofía francesa, aunque ello no se lleve a cabo de manera complaciente ${ }^{15}$. La posibilidad de un diálogo menos conflictivo con la filosofía francesa habilitó una recepción muy favorable de ella en el ámbito alemán. Mientras la oposición alemana, principalmente, encabezada por Habermas contra el pensamiento francés no tuvo el fruto esperado, las editoriales más importantes de Alemania publicaban numerosas obras de autores franceses. Así, se abrió la posibilidad tanto para la lectura de Lyotard, Derrida, Lacan y Foucault como de pensar los nuevos procesos socio-políticos en Alemania sin la tutela del paradigma de la Teoría Crítica y Habermas.

Ciertamente, el propio Frank ha reconocido en una entrevista realizada por Raúl Fornet-Betancourt y Klaus Hedwig (1988) que el texto de Habermas tiene presente, evidentemente, sus huellas. Pero, también en dicha entrevista, Frank reconoce que su texto tenía como propósito establecer un diálogo de aprendizaje con las corrientes francesas, pero encontró más resistencias de las que imaginó. Por lo tanto, su posición muestra una pronunciada ambigüedad

\footnotetext{
${ }^{13}$ Para ampliar estas consideraciones véase Frank (2004b).

${ }^{14}$ La traducción de los artículos presentados en el primer encuentro en París, beneficiado Philippe Forget en 1981, entre Hans-Georg Gadamer y Jacques Derrida constituye una de las más clarificadoras publicaciones en castellano sobre los debates franco-alemanes.

${ }^{15}$ La intención de Frank (1976) por establecer un diálogo productivo con la filosofía francesa aparece a fines de los años 70 en un texto acerca de Derrida.
} 
respecto al neoestructuralismo. En Francia las lecciones sobre el neoestructuralismo de Frank ayudaron a aumentar el rechazo a la filosofía alemana y, en Alemania, por su parte, permitió despertar el interés en el estudio de estas corrientes, como también, su rechazo.

En esa dirección, Habermas, tanto en "La modernidad, un proyecto incompleto" como en El discurso filosófico de la modernidad, muestra una profunda resistencia a la filosofía francesa, calificando a los jóvenes franceses de conservadores, irracionales y emocionales ${ }^{16}$. Las críticas de Habermas, fundamentalmente, están dirigidas en contra de las intenciones de la filosofía francesa por pretender dar muerte al sujeto. Estas críticas son bastante similares a las críticas al neoestructuralismo que Frank lanza en su texto $L a$ piedra de toque de la individualidad, que hemos repasado en el punto tres de nuestro trabajo, antes que en sus lecciones bajo el título ¿Qué es el neoestructuralismo? En este contexto, la posición de Frank adquiere una notable relevancia en tanto permite entender cómo la recepción alemana de la filosofía francesa se dividió en un rechazo rotundo en Habermas, mientras que en otros círculos intelectuales como los de Werner Hamacher, Peter Szondi o Rainer Nägele benefició un encuentro radical para renovar las propias tradiciones alemanas ${ }^{17}$.

En un texto traducido con el nombre de "Integración sin entusiasmo", Frank muestra la ambivalente relación (rechazo y asimilación) que la filosofía alemana establece con la filosofía francesa. En este escrito, sostiene que la filosofía debe enfrentarse a dos tareas: "abrir la puerta a la esperanza y gestionar la resignación" (2004, p.7). Esa doble tarea que la filosofía asumiría es la que enfrenta Alemania en los años 80 con la filosofía de mayo del 68. Para Frank, el ingreso de la filosofía francesa encuentra un contexto desfavorable para su

\footnotetext{
${ }^{16}$ Dice Habermas: "Los jóvenes conservadores recapitulan la experiencia básica de la modernidad estética. Afirman como propias las revelaciones de una subjetividad descentralizada, emancipada de los imperativos del trabajo y la utilidad, y con esta experiencia salen del mundo moderno. Sobre la base de las actitudes modernistas justifican un antimodernismo irreconciliable. Relegan a la esfera de lo lejano y lo arcaico los poderes espontáneos de la imaginación, la propia experiencia y la emoción. De manera maniquea, yuxtaponen a la razón instrumental un principio sólo accesible a través de la evocación, ya sea la fuerza de voluntad o la soberanía, el Ser o la fuerza dionisiaca de lo poético. En Francia esta línea conduce de Georges [Bataille], a través de Michel Foucault, a Jacques Derrida" (1985, p. 34).

${ }^{17}$ Véase Gemünden (1989, pp. 182-185) y Holub (1984). Este último autor sostiene que la recepción de Frank permitió una recepción radical de las tesis postestructuralistas, al punto tal que se podría hablar de la formación de un "postestructuralismo alemán".
}

Garnica, N. (2018). Asimilación y rechazo de la filosofía francesa en Alemania. La recepción de Manfred Frank: romanticismo, hermenéutica y deconstrucción. 
recepción, pues ni las ciencias, ni la filosofía encontraban en ese momento respuestas a la "crisis de sentido". No obstante, algunos espacios intelectuales alemanes, siguiendo las huellas de las lecciones de Frank, lograron acceder a las lecturas de los pensadores franceses. Efectivamente, como ha explicado Gérard Raulet:

Las lecciones pronunciadas en Düsseldorf y Ginebra por Manfred Frank y publicadas con el título Was ist Neo-Strukturalismus? en 1983 tuvieron mucho que ver con ello. Iniciaron a toda una generación de jóvenes filósofos de habla alemana en los nuevos enfoques franceses. La fuerza innovadora de los autores franceses arremetió contra una Teoría Crítica que, en la persona de Jürgen Habermas, se renovaba ciertamente de manera inexorable pero lenta. Invitado al College de France en 1983, este último adoptó como estrategia una ofensiva frontal contra las corrientes francesas; ya en 1980, cuando recibió el Premio Adorno de la ciudad de Fráncfort, había mostrado sus cartas en "La modernidad, un proyecto inacabado", al calificar de neoconservadurismo "la tendencia que va de Georges Bataille a Derrida, pasando por Foucault" [...] Esta (contra) ofensiva se publicó en alemán en 1985 con el título El discurso filosófico de la modernidad; tuvo como resultado que se abrieran las compuertas para recibir al postestructuralismo y al pensamiento postmoderno en Alemania. Manfred Frank tiene no solo el inmenso mérito de presentar, en forma de lecciones universitarias aparentemente neutras, las corrientes incriminadas, sino también de comprometerse para entablar un diálogo de base con los pensadores franceses; con ello contribuyó, sin compartir por ello el entusiasmo de los pequeños editores que se pusieron a publicar todo lo que venía de Francia, a afianzar la referencia al postestructuralismo francés en los debates filosóficos alemanes. Desde entonces, paralelamente a los pequeños editores como Merve, los grandes, principalmente Suhrkamp, incluyeron a los filósofos franceses entre los valores seguros de sus programas. Hubo más textos de Derrida, Foucault, Lyotard, Baudrillard, etc. traducidos al alemán que en un primer momento, de Habermas y la Teoría Crítica en su conjunto traducido al francés. Un efecto de esta coyuntura franco-alemana es que, por el lado francés, Foucault admitió, en una entrevista que dio la vuelta al mundo, que sus posiciones no eran en nada incompatibles con las de la Escuela de Fráncfort, al menos con el diagnóstico de la autodestrucción de la Razón formulado en Dialéctica de la Ilustración (1944) (2009, pp. 289-290).

Justamente, Frank indica que con la llegada de la década del 80 la crisis del sentido se agudizó en distintos puntos intelectuales llevando a la desilusión, la desesperanza y la sospecha sobre los valores heredados por la modernidad. Todo aquello que era claro y distinto, racional y ordenado comenzó a ser reemplazado por una nueva norma: la falta de claridad. Frank cree que 
tal norma dio lugar al posmodernismo o neoestructuralismo como un nuevo pathos intelectual en distintas disciplinas desde la literatura hasta las ciencias sociales pasando por la política. La emergencia de esta nueva situación intelectual presiona sobre la filosofía alemana y obliga a la misma a llevar a cabo un tipo de integración de dicha situación novedosa. Pero, esa integración se encuentra atravesada, por una parte, por la agonía de la perdida y, por otra parte, por la resistencia a la vuelta de sus propias raíces que la filosofía alemana quiere negar ${ }^{18}$.

En conclusión, la explicación de Frank, acerca de la relación entre Francia y Alemania en la filosofía de los años 80 , podría hacernos notar que el punto de confrontación más fuerte entre ambas esferas intelectuales pueda estar en la lectura e interpretación que cada una lleva a cabo de lo que entendemos por tradición filosófica. El rechazo o la asimilación de la filosofía francesa en Alemania parecieran estar mediados por el modo en que se lleva a cabo la lectura de la tradición filosófica, algo que Frank identifica con el aspecto problemático de las fuentes. El pensador alemán sostiene que esa polaridad de rechazo e integración "sólo puede presentarse como subordinación a quien deja que esta prehistoria de la crítica a la modernidad y al logocentrismo se evapore de sus estudios en lugar de verificarla en las fuentes" (2004, p. 12). Esto no quiere decir que existiría una especie de demarcación entre una lectura correcta e incorrecta de la tradición. Antes bien, pretende advertir sobre cómo las reelaboraciones conceptuales de la tradición filosófica pueden llegar a conclusiones estrepitosas si no indagamos en sus fuentes.

\section{Referencias}

Badiou, A. (2013). La aventura de la filosofia francesa. A partir de 1960. Bs. As.: Eterna Cadencia.

Bowie, A. (1996). The Meaning of the Hermeneutic Tradition in Contemporary Philosophy. Lecture given at the Royal Institute of Philosophy Series, 23rd February, pp. 1-30.

Brunschvicg, L. (1939). Prólogo. Gurvitch, G. Las tendencias actuales de la filosofía alemana. Bs. As.: Edit. Losada.

\footnotetext{
${ }^{18}$ Se pueden ampliar estas reflexiones en el volumen colectivo preparado por Gérard Raulet (2017).

Garnica, N. (2018). Asimilación y rechazo de la filosofía francesa en Alemania.

La recepción de Manfred Frank: romanticismo, hermenéutica y deconstrucción.

Cuestiones de Filosofía, 4 (22), 37-67. 
Critchley, S. y Honneth, A. (2003). La filosofía en Alemania. Farfán Hernández, R y Girola, L. (Comps.). Cultura y civilización. El pensamiento crítico alemán contemporáneo (pp. 237-258). México: Editorial Universidad Autónoma Metropolitana.

Descombes, V. (1988). Lo mismo y lo otro. Cuarenta y cinco años de filosofía francesa (1933-1978). Madrid: Cátedra.

Derrida, J. (1994). Márgenes de la filosofia. Madrid: Cátedra.

Derrida, J. (1997). La diseminación. Madrid: Editorial Fundamentos.

Frank, M. (1976) Eine fundamental-semiologische Herausforderung der abendlandischen Wissenschaft: Jacques Derrida. Philosophische Rundschau, 23, pp. 1-16.

Frank, M. (1998). Los límites de la controlabilidad del lenguaje. La conversación como lugar de la diferencia entre neoestructuralismo y hermenéutica. Cuaderno Gris, 3, pp. 89-98.

Frank, M. (1985). Das Individuelle Allgemeine: Textstrukturierung und Textinterpretation nach Schleiermacher. Frankfurt/Main: Suhrkamp.

Frank, M. (1988). Die Vernuft im Prozeß der dezentralisierten Diskurse. Ein Interview mit Manfred Frank (mit Klaus Hedwig). Concordia, 13, pp. $2-27$.

Frank, M. (1995). La piedra de toque de la individualidad. Reflexiones sobre sujeto, persona e individuo con motivo de su certificado de defunción postmoderno. Barcelona: Herder.

Frank, M. (1997). Subjetivity and Individuality: Survey of a Problem. Klemm, D. and Zoller. G. (Eds.), Figuring the self: subject, absolute, and others in classical German philosophy (pp. 3-30). Albany: SUNY Press.

Frank, M. (2004a). Integración sin entusiasmo. La filosofía alemana entre la asimilación y el rechazo de la tradición. Revista de Occidente. Pensar en alemán hoy. Vuelve la Ilustración, 282, pp. 5-14.

Frank, M. (2004b). The Philosophical Foundations of Early German Romanticism. New York: State University of New York Press. 
Frank, M. (2011). ¿Qué es el neoestructuralismo?. México: FCE.

Gemünden, G. (1989) Der Unterschied Liegt in Der Differenz: On Hermeneutics, Deconstruction, and Their Compatibility. New German Critique, 48 (Autumn), pp. 176-192.

Gutting, G. (2001). French philosophy in the twentieth century. Cambridge: Cambridge University Press.

Gutting, G. (2011). Pensando lo imposible. Filosofía francesa desde 1960. Madrid: Avarigani.

Habermas, J. (1985). La modernidad, un proyecto incompleto. Hal Foster (Ed.). La posmodernidad (pp. 19-36). Barcelona: Kairós.

Hauge, H. (1990). The Will to Consensus: Manfred Frank on Derrida. German Issue, 105 (3), pp. 596-609.

Holub, R. (1984). Politicizing Post-Structuralism: French Theory and the Left in the Federal Republic and in the United States. The German Quarterly, 57(1), pp. 75-90.

Pippin, R. (2005). On Not Being a Neo-Structuralist: Remarks on Manfred Frank and Romantic Subjectivity. The persistence of the subjectivity (pp. 168-185). New York: Cambridge University Press.

Raulet, G. (2006). La filosofía alemana después de 1945. Valencia: Universidad de Valencia.

Raulet, G.; Schnädelbach, H.; Frank, M.; Stäblein, R.; Vetter, H.; Poulain, J. \& Garnica, N. (2017). Ecos filosóficos del mayo francés en Alemania. Bs. As.: Miño y Dávila.

Schleiermacher, F. (1990). Ethik. Hamburg: Meiner.

Waldenfels, B. (1997). Introducción a la fenomenología. De Husserl a Derrida. Bs. As.: Paidós. 